DOI: https://doi.org/10.46667/renbio.v13i1.291

\title{
A educação alimentar e nutricional no ensino de ciências/biologia à luz das publicações na SBEnBio
}

\author{
Food and nutritional education in science/biology teaching in the light of \\ publications in SBEnBio
}

\author{
Francisco Nunes de Sousa Moura ${ }^{1}$, Raquel Crosara Maia Leite ${ }^{2}$ \\ José Arimatéa Barros Bezerra ${ }^{3}$
}

\begin{abstract}
Resumo
Considerando a relevância de discussões voltadas à Educação Alimentar e Nutricional (EAN), objetivou-se neste trabalho averiguar as produções relacionadas à alimentação saudável em vieses de currículo escolar, formação de professores e estratégias didáticas no Ensino de Ciências/Biologia. Para isso, realizou-se uma revisão de literatura nas edições do Encontro Nacional de Ensino de Biologia e da Revista de Ensino de Biologia, visto os seus protagonismos em discussões no campo das Ciências Naturais. Dos quarenta artigos identificados, teve-se publicações voltadas ao currículo escolar (1), à formação de professores (11) e a estratégias didáticas (28), remetendo a EAN em diversos contextos. Assim, tal temática tem sido discutida na educação em ciências, propiciando uma melhor formação dos sujeitos escolares - licenciandos, professores e alunos.
\end{abstract}

Palavras-chave: Alimentação saudável. Educação em saúde. Educação científica.

\begin{abstract}
Considering the relevance of discussions focused on Food and Nutritional Education (EAN), the objective of this work was to investigate the productions related to healthy eating in school curriculum bias, teacher training and didactic strategies in Science / Biology Teaching. To this end, a literature review was carried out in the editions of the National Meeting on Teaching Biology and the Journal of Teaching Biology, given their role in discussions in the field of Natural Sciences. Of the forty articles identified, there were publications focused on the school curriculum (1), teacher training (11) and didactic strategies (28), referring to EAN in different contexts. Thus, this theme has been discussed in science education, providing better training for school subjects - undergraduates, teachers and students.
\end{abstract}

Keywords: Healthy eating. Health education. Science education.

\footnotetext{
${ }^{1}$ Licenciado em Ciências Biológicas - Universidade Federal do Ceará (UFC). Fortaleza, CE - Brasil. Mestrando em Educação Brasileira - Universidade Federal do Ceará (UFC). Fortaleza, CE - Brasil. E-mail: nunes.moura@alu.ufc.br

${ }^{2}$ Doutora em Educação - Universidade Federal de Santa Catarina (UFSC). Florianópolis, Brasil. Docente associado I - Universidade Federal do Ceará (UFC). Fortaleza, CE - Brasil. E-mail: raquelcrosara@hotmail.com

${ }^{3}$ Doutor em Educação Brasileira - Universidade Federal do Ceará (UFC). Pós-doutor em História Universidade Federal do Paraná (UFPR). Curitiba, PR - Brasil. Docente Associado - Universidade Federal do Ceará (UFC). Fortaleza, CE - Brasil. E-mail: jotabarrosbezerra@ gmail.com

Submetido em: 27/03/2020 - Aceito em: 21/06/2020
} 
DOI: $\underline{\text { https://doi.org/10.46667/renbio.v13i1.291 }}$

\section{Introdução}

O Ensino de Ciências/Biologia, na Educação Básica, contribui para o desenvolvimento de sujeitos que possam compreender, opinar, atuar e intervir em diversas situações sociocientíficas (CACHAPUZ et al., 2011). Neste cerne, tal ensino deve propiciar uma preparação abrangente, com o intuito de compreensão dos fenômenos naturais ao estarem no interior e exterior das escolas (DELIZOICOV; ANGOTTI; PERNAMBUCO, 2018). Assim, a formação dos alunos se associa com a realidade, envolvendo-os em diversos aspectos e fenômenos científicos que os rodeiam (CACHAPUZ, 2012).

Nesta perspectiva, uma articulação interdisciplinar e contextualizada entre as Ciências da Natureza com as demais Ciências se torna significativa, emergindo visões críticas da realidade Científica e Tecnológica, sendo criadas pela e para a Sociedade (CAMPOS et al., 2019). Com uma formação científica efetivada, os discentes estarão aptos a mudanças sociais e ambientais necessárias na contemporaneidade, pois poderão aplicar os saberes a aspectos em escala global (ARAÚJO; LEITE, 2019).

Não obstante, na efetivação dos escritos, a educação científica perpassa por diversos entraves para a sua consolidação na aprendizagem, tais como uma maior preocupação externa com os trabalhos, com as notas, entre outras atividades pelos discentes do que com o aprendizado em Ciências (KRASILCHIK, 2004). Isso demonstra que é necessário refletir sobre a construção curricular das instituições de ensino, a formação de professores e as estratégias didáticas para concretizar as propostas do Ensino de Ciências/Biologia. As limitações resultam no baixo desempenho de aprendizagem dos alunos, além da frágil atuação destes em sociedade (POZO; CRESPO, 2009).

Os problemas descritos resultam em consequências nas diversas temáticas promovidas pelas Ciências, as quais são urgentes de discussão na atualidade, como por exemplo a Educação Alimentar e Nutricional (EAN). Segundo Ramos, Santos e Reis (2013), as produções sobre a alimentação saudável são incipientes no campo científico e as publicizações correspondem a intervenções com metodologias de ensino, em predomínio, de cunho tradicional. Complementarmente, Boog (2013) relata outra problemática relacionada a este ensino, visto a sua aplicação majoritária com abordagens biomédicas, o que impede de entender a alimentação como um comportamento humano. Contudo, de acordo com Mohr (2002), isso decorre pela abordagem de temas amplos da Saúde e das Ciências da Natureza a apenas uma de suas características, a biológica. Desta forma, compreende-se que é preciso perpassar estas áreas em diversos âmbitos, além do biológico.

Tais relatos são preocupantes, pois reflexões e mudanças nos hábitos alimentares dos brasileiros são necessárias. Segundo dados do Ministério da Saúde, somos uma população com comportamento alimentar inadequado, aumentando os índices de obesidade e problemas de saúde (BRASIL, 2019a). Neste sentido, reconhecendo tal problemática social, as políticas educacionais optaram pela inserção da EAN como um dos temas contemporâneos transversais 
DOI: $\underline{\text { https://doi.org/10.46667/renbio.v13i1.291 }}$

(BRASIL, 2019b), na qual deve circundar todos os componentes curriculares obrigatórios das instituições de ensino básico.

Seguindo a linha de raciocínio, como uma temática científica, a EAN deve ser planejada com perspectiva de preparação cidadã, envolvendo aspectos sociais, culturais, éticos, ambientais, entre outros (PRADO et al., 2016). Isso permite uma integralização entre a ciência da nutrição e o comportamento alimentar, na tentativa de estudos da alimentação saudável com todos os seus elementos. Desta forma, as premissas devem ser discutidas na formação de profissionais para atuar na área, como nutricionistas, professores e outros (BEZERRA, 2018). Especificamente, nas diretrizes curriculares para o curso de licenciatura em Ciências Biológicas, enfatiza-se a propagação do ensino de saúde (BRASIL, 2001), devendo os profissionais formados reconhecerem a sua relevância nos fatos das Ciências Naturais.

Diante das dificuldades e limitações na efetivação das propostas do Ensino de Ciências/Biologia, refletidas em temáticas científicas, a saber, a EAN, a seguinte indagação norteadora deste artigo emergiu pelos autores: como a Educação Alimentar e Nutricional tem sido promovida no Ensino de Ciências/Biologia em vieses de currículo, formação de professores e estratégias didáticas? Este tripé representa os norteamentos e as ações da EAN no contexto escolar e na preparação de profissionais atuantes ou em formação nesta área.

Com este trabalho, pretende-se investigar a temática específica da alimentação saudável, e como ela tem sido perpassada ao longo de publicações nacionais, como as postuladas pela Associação Brasileira de Ensino de Biologia (SBEnBio). Tal associação, criada em 1997, é renomada na promoção do avanço da pesquisa e do Ensino de Biologia entre os professores e pesquisadores deste campo do conhecimento ${ }^{4}$.

A SBEnBio realiza eventos regionais (EREBIO) e nacionais (ENEBIO), publica os trabalhos apresentados, bem como edita a revista de Ensino de Biologia (REnBio), possibilitando assim diversas formas de comunicação com as temáticas científicas. As primeiras publicações promovidas pela associação datam de 2005, período de diálogos necessários quanto ao Ensino de Ciências/Biologia, após a divulgação das diretrizes curriculares para o curso em ênfase e outros documentos educacionais da época para o ensino básico, como os Parâmetros Curriculares Nacionais - PCN.

Vale ressaltar que as discussões neste campo são de caráter significativo para a compreensão dos postulados de Ensino de Ciências/Biologia no meio científico e acadêmico. As proposições são relevantes em virtude de a temática alimentação saudável estar centrada nos assuntos do componente curricular de Ciências da Natureza, segundo documentos oficiais da educação, como os PCN (BRASIL, 1997a) e a Base Nacional Comum Curricular - BNCC

\footnotetext{
${ }^{4}$ As presentes informações foram extraídas da página da Associação Brasileira de Ensino de Biologia - SBEnBio. Disponível em: https://sbenbio.org.br/ . Acesso em 18 de janeiro de 2020.
} 


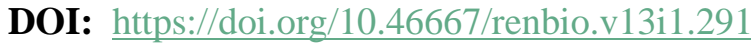

(BRASIL, 2019b), embora esteja exposto também como transversal. Assim, o foco desta pesquisa consiste no debate de disseminação da EAN na área de Ciências da Natureza.

Conforme o exposto, objetiva-se neste artigo averiguar, a partir de uma revisão de literatura, as publicações sobre a alimentação saudável no Ensino de Ciências/Biologia na perspectiva de currículo escolar, formação de professores e estratégias didáticas, com o intento da análise de divulgações das pesquisas referente a políticas educacionais e ações de docentes (formados e em formação) com tal temática. A seguir, veremos as delimitações metodológicas para as buscas.

\section{Construindo o caminho metodológico}

Com uma abordagem qualitativa, este trabalho é caracterizado como exploratório e descritivo. Ele incide em uma revisão de literatura das publicações na Associação Brasileira de Ensino de Biologia (SBEnBio) sobre a temática alimentação saudável em vieses de currículo escolar, da formação de professores e das práticas metodológicas de ensino. As buscas, leituras e anotações foram norteadas de acordo com os postulados de Lima e Mioto (2007).

A escolha pela SBEnBio se deu em virtude dos seguintes motivos: 1 - pela sua relevância e reconhecimento na divulgação do Ensino de Biologia, bem como de temáticas científicas; e 2 - por reunir diversas produções de eventos regionais, nacionais e de fluxo contínuo. Neste levantamento bibliográfico, procurou-se as publicações do ENEBIO e da REnBio, pois reúnem trabalhos completos das proposições dos temas divulgados, além de obtermos pesquisas direcionadas ao evento nacional e de fluxo contínuo na revista.

Para a procura das informações, utilizou-se, de forma simples, os termos "Alimentação" e "Nutrição". A detecção e a seleção inicial de trabalhos ocorreu com a leitura dos títulos, seguidas dos resumos e, se necessária, de todo o trabalho, haja vista que em alguns casos, a divulgação da Educação Alimentar e Nutricional (EAN) se deu pela reflexão da formação docente e das estratégias didáticas, onde só notamos a presença da temática enfatizada em momentos posteriores da leitura.

No tocante ao recorte temporal dos achados, este foi de acordo com o início das divulgações da SBEnBio, ou seja, a partir do ano de 2005 até as últimas publicações antes de se realizar a presente pesquisa. No total, houve sete edições do ENEBIO (2005-2018); e quatorze edições da revista (2005-2019), sendo uma de número zero, outra especial e as duas últimas divididas em dois números ao ano. Porém, destaca-se que quatro das edições da REnBio são frutos de apresentações do ENEBIO, nas quais as edições 3 (2010), 5 (2012), 7 (2014) e 9 (2016) da revista correspondem às edições III, IV, V e VI do ENEBIO. As demais publicações são de análises do fluxo contínuo na revista e nos demais anais do evento.

Após a obtenção dos dados, estes foram interpretados mediante a Análise de Conteúdo de Bardin (2011). Tais resultados estão presentes na seção a seguir, segmentado nos dois seguintes subtópicos: as caracterizações temporais e regionais das publicações e a 


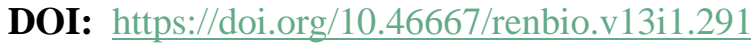

abordagem da alimentação saudável em currículo escolar, formação de professores ou estratégias didáticas.

\section{Resultados e discussão}

Percorrido todo o caminho metodológico, detectou-se quarenta trabalhos, divididos em anais do ENEBIO ou de publicações da REnBio. O quadro 1 apresenta a quantificação das identificações quanto ao ano e às edições dos achados, caracterizando-os mediante Revista, Evento ou Revista e Evento, seguindo nas duas últimas situações a exposição dos estados brasileiros de realização dos eventos. No presente quadro, mostrou-se também as seguintes descrições sobre os artigos $^{5}$ : relato de experiência (RE) ou relato de pesquisa, sendo este último designado de forma concluída (RPC) ou em andamento (RPA).

Quadro 1. Descrição dos achados ao longo do caminho metodológico.

\begin{tabular}{|c|c|c|c|c|c|c|}
\hline Ano & Edição & Publicados & Selecionados & $\mathbf{R E}$ & RPA & RPC \\
\hline 2007 & II ENEBIO/MG & 219 & 2 & - & - & 02 \\
\hline 2010 & III ENEBIO - CE/ No 3 Revista & - & 2 & 01 & - & 01 \\
\hline 2012 & IV ENEBIO - GO/ No 5 Revista & 331 & 1 & - & - & 01 \\
\hline 2014 & V ENEBIO - SP/ No 7 Revista & 568 & 10 & 04 & 01 & 05 \\
\hline 2016 & VI ENEBIO - PR/ Nº 9 Revista & 699 & 12 & 09 & 01 & 02 \\
\hline \multirow{2}{*}{2018} & VII ENEBIO - PA & 902 & 12 & 05 & 02 & 05 \\
\hline & $\mathrm{N}^{\mathrm{o}} 11$ Revista & 17 & 1 & - & - & 01 \\
\hline \multicolumn{3}{|c|}{ Total de trabalhos selecionados } & 40 & 19 & 04 & 17 \\
\hline
\end{tabular}

Fonte: $\mathrm{SBEnBio}^{6}$.

Os dados do quadro 1 são subsídios informativos para as duas próximas subseções do presente trabalho. Nestas duas divisões, intentemos caracterizar no âmbito temporal e regional as publicações identificadas, bem como apresentar os principais achados ao longo das investigações. Neste sentido, a seguir, aborda-se a tipificação das pesquisas.

\footnotetext{
${ }^{5}$ Os trabalhos considerados como relatos de experiências foram os que tiveram maior/integral foco na exposição das atividades propostas, ainda que se tenha ocorrido o uso de demais metodologias científicas para a aquisição de dados opinativos dos sujeitos investigados referentes às suas vivências com as ações pedagógicas. Enquanto isso, denominou-se relatos de pesquisas concluídas, as investigações acadêmicas finalizadas e as de recorte de pesquisas mais amplas, pois respondem a uma problemática a partir da consolidação dos achados. Nas investigações em andamento, considerou-se os relatos da construção de produtos que não foram aplicados e, assim, faltam dados da sua eficiência, além da possibilidade de responder com êxito a problemática que incitou a sua produção.

${ }^{6}$ As numerações do ENEBIO foram informadas na apresentação dos anais, exceto o III que não houve divulgação. Quanto a revista, somou-se os artigos publicados ao longo de todo o ano de 2018.
} 
DOI: $\underline{\text { https://doi.org/10.46667/renbio.v13i1.291 }}$

\section{Conhecendo os achados da caminhada}

Durante as averiguações foram encontradas diversas publicações relacionadas às mais variadas temáticas do Ensino de Ciências/Biologia e de divulgação científica. Todavia, com a delimitação da procura traçada, foram selecionados os trabalhos que possuíam relação com a promoção da Educação Alimentar e Nutricional (EAN) no currículo escolar (1 pesquisa), na formação de professores (11 trabalhos) e nas estratégias didáticas (28 pesquisas), totalizando os quarenta achados.

Verifica-se a partir do quadro 1 que o número de produções voltadas à EAN vem aumentando ao longo dos anos. Isso é corroborado ao observar o maior número de produções nas últimas edições analisadas, inclusive com o início de publicações em fluxo contínuo da REnBio, na qual foi percebido uma produção. As demais publicações aconteceram em virtude da divulgação no ENEBIO, evento que contemplou todas as regiões brasileiras.

É interessante enfatizar que outras pesquisas referentes à alimentação saudável foram constatadas durante o percurso das buscas. Contudo, elas não foram consideradas por causa das seguintes explicações: 1 - abordagens superficiais dos nutrientes vinculadas a bioquímica ao invés da alimentação; 2 - alto foco na explanação da metodologia aplicada e baixa na promoção da EAN; 3 - trabalhos de áreas técnicas, como análise curricular de um curso de alimentos; e 4 - muitos trabalhos, por exemplo com relatos da produção de hortas, apresentavam a alimentação saudável de forma secundária, enfatizando-se demais áreas do conhecimento, tais como ecologia, botânica e outras.

O último motivo (quarto) serviu de ponderação no presente trabalho, visto que reflexões sobre a EAN devem possuir o seu "próprio corpo", e não devem ser apresentadas de forma secundária ou como membro de outras temáticas. O presente relato é confirmado com a observação da EAN adicionada como temática transversal nos currículos das escolas brasileiras (BRASIL, 2018), o que sugere maiores focos e centralidades neste tema.

As premissas contribuem na valoração desta temática necessária de discussão na atualidade. Emergida já de forma tardia no Brasil, apenas nos anos de 1990, ela vem perpassando por diversas políticas públicas e setores educacionais (BRASIL, 2012). Apesar dos primeiros achados serem datados em 2007 na SBEnBio, políticas públicas sobre a EAN no campo da educação já tinham sido propagadas, como a adição do tema alimentação saudável na proposta transversal da saúde nos PCN (BRASIL, 1997b), em postulados de documentos curriculares nacionais do ensino de Ciências da Natureza (BRASIL, 1997a), no acordo interministerial entre o Ministério de Saúde e o Ministério da Educação para a promoção da alimentação saudável nos espaços escolares (BRASIL, 2006a), entre outras decisões oficiais. 
DOI: $\underline{\text { https://doi.org/10.46667/renbio.v13i1.291 }}$

Neste sentido, constata-se que o início das discussões relacionadas a EAN se deu em períodos recentes de tempo, menos de 20 anos. Em pesquisas similares a esta sobre a promoção da alimentação saudável, detectou-se também achados somente após o ano de 2005 (FIGUEIRA; LIMA; SELLES, 2016; SANTOS; OLIVEIRA; MEIRELLES, 2014; MENON; COELHO NETO; BERNARDELLI, 2018). Isso pode ter ocorrido pelo surgimento de interesse pela temática a partir dos anos 2000, possível período de visualização dos resultados da inclusão da EAN nos espaços escolares e de intensificação das políticas públicas.

Outra verificação aconteceu na regionalidade de divulgação das pesquisas. Como informado anteriormente, o ENEBIO abrangeu todas as regiões brasileiras, embora em algumas tenha ocorrido mais de uma vez, como se observa no quadro 1. Todas as regiões tiveram presença de trabalhos sobre a temática em realce, nas quais possuem as subsequentes quantificações: Centro-Oeste (2), Nordeste (11), Norte (7), Sudeste (17) e Sul (3). A figura 1 mostra a divisão de trabalhos pelos estados brasileiros.

Figura 1. Divisão de produções por cada estado do Brasil.

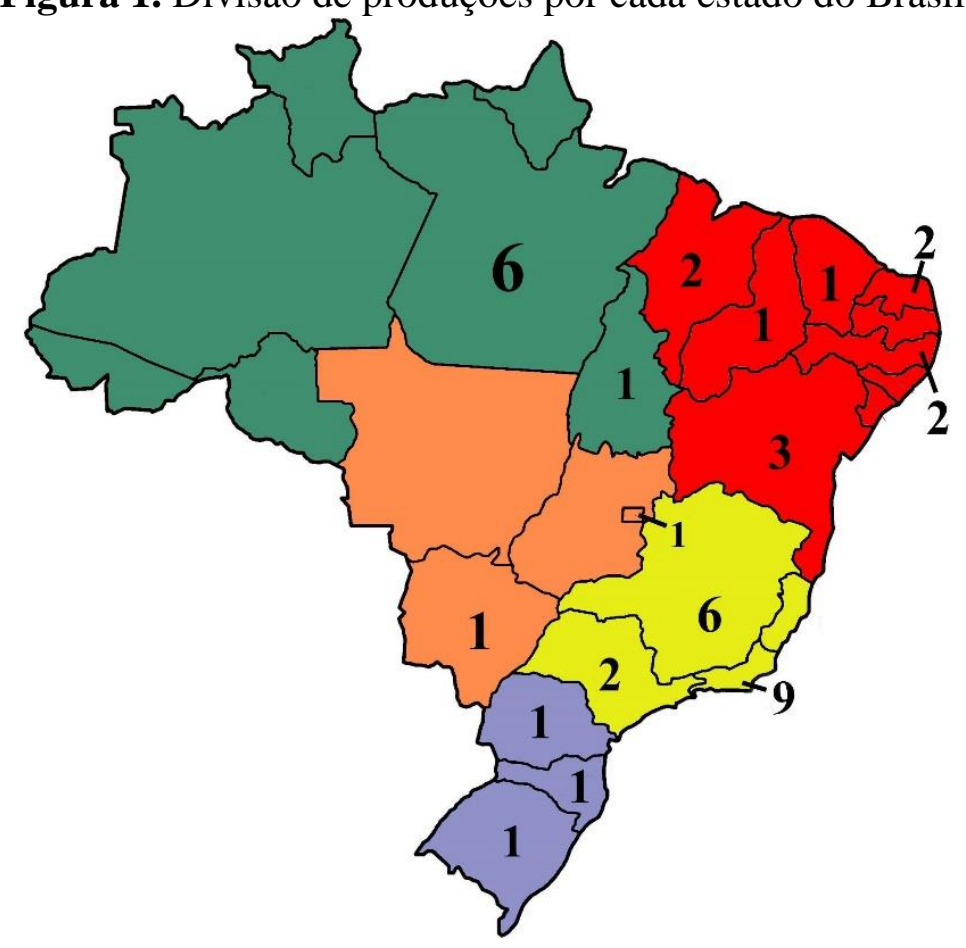

Fonte: InfoEscola ${ }^{7}$.

\footnotetext{
${ }^{7} \mathrm{O}$ mapa foi obtido da plataforma InfoEscola e utilizado apenas para edição das informações. Disponível em: <https://www.infoescola.com/geografia/mapa-do-brasil/>. Acesso em: 26 de janeiro de 2020.
} 


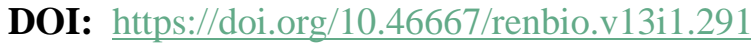

Pode-se averiguar a produção de trabalhos em todas as regiões brasileiras, apesar de alguns estados (11) não terem trabalhos publicados nas edições da SBEnBio no viés desta pesquisa. A região Sudeste do Brasil lidera com o maior número de divulgações (17), inclusive o Rio de Janeiro é o estado que mais possui publicações (9), seguido de Minas Gerais (6) e do Pará (6) na região Norte. Outra região com grande número de produções é o Nordeste (11), com trabalhos publicados em seis de nove estados, com destaque para o estado da Bahia (3).

A pouca produção de trabalhos na SBEnBio pode ser reflexo da lenta consolidação de programas de promoção da saúde nos diversos estados e municípios brasileiros, os quais não ganharam realce por todo o país (BUSS; CARVALHO, 2009). Complementarmente, embora a inserção de profissionais preparados, como os nutricionistas, para a execução de projetos governamentais, entre eles o Programa Nacional de Alimentação Escolar (PNAE), tenha crescido no Brasil, a sua distribuição é desigual entre as suas regiões (CHAVES et al., 2013).

Os destaques são fundamentais na visualização de possíveis atrasos de aplicabilidade da EAN nos mais variados espaços brasileiros, até mesmo para políticas públicas da Educação, chegando às salas de aula ou aos ambientes externos a estas, no caso das cantinas escolares. Sobre este último, em uma pesquisa da constituição dos cardápios escolares das regiões do Brasil, Chaves et al. (2009) identificaram a falta da produção dos cardápios alimentares por nutricionistas, ainda que ocorra de forma majoritária por este profissional nos estados e nas cidades deste país, além da ausência de uma valorização da cultura de cada região. Isso aponta ser preciso inserir tal profissional nas escolas e valorizar os saberes culturais das regiões, associando o ensino dos professores com tal vivência nas instituições de ensino básico.

Como mencionado, além das cantinas, a promoção da alimentação saudável é feita em sala de aula. No que tange aos sujeitos das pesquisas (público-alvo), o quadro 2 apresenta os indivíduos envolvidos. Reitera-se que algumas das investigações utilizaram mais de uma das categorias de sujeitos citados, o que na contagem final ultrapassa as quarenta pesquisas.

Quadro 2. Público-alvo dos artigos identificados.

\begin{tabular}{|l|c|}
\hline Sujeitos investigados nas pesquisas & Quantidade de trabalhos \\
\hline Alunos da Educação Infantil & 01 \\
\hline Alunos dos Anos Iniciais do Ensino Fundamental & 07 \\
\hline Alunos dos Anos Finais do Ensino Fundamental & 14 \\
\hline Alunos do Ensino Médio & 09 \\
\hline Alunos da Educação Básica & 03 \\
\hline Alunos do Ensino Superior & 02 \\
\hline Alunos da Educação de Jovens e Adultos - EJA & 02 \\
\hline Alunos da EJA, modalidade Especial & 01 \\
\hline Professores da Educação Básica & 05 \\
\hline Participantes de Programas de Iniciação à Docência & 02 \\
\hline
\end{tabular}

Fonte: Artigos da SBEnBio. 


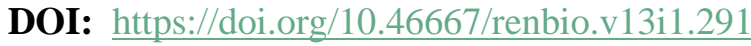

Atenta-se que as investigações abrangem diversos níveis e modalidades de ensino. Todavia, faltam trabalhos com foco nos professores formadores, pois embora a maioria das publicações seja oriunda das orientações e/ou participações destes profissionais, torna-se importante a sua presença como pesquisado, visto a sua relevância para a preparação de professores. Tal vertente contribui na identificação de possíveis diminuições/superações de dificuldades dos licenciandos em posteriores práticas docentes, bem como é necessário investigar as concepções, as formações acadêmicas, as práticas metodológicas, entre outras vertentes que circundam a atuação dos professores formadores, as quais refletem na preparação de qualidade dos docentes em formação inicial (OLISKOVICZ; PIVA, 2012).

As duas maiores quantificações de sujeitos são dos Anos Finais do Ensino Fundamental e os do Ensino Médio. As premissas podem ter ocorrido porque apesar do professor de Ciências/Biologia ser formado para atuar por todo o Ensino Fundamental e Médio (BRASIL, 2001), cabe aos formados em Pedagogia o ensino para atuar na Educação Infantil e nos Anos Iniciais do Ensino Fundamental (BRASIL, 2006b). Assim, nos Anos Iniciais, a promoção desta temática é realizada por profissionais pedagogos, enquanto nos Anos Finais ocorre por docentes preparados nos cursos das áreas de Ciências.

Neste ensejo, ainda que a EAN seja um tema científico, a sua divulgação é mínima por pedagogos no ENEBIO e/ou na REnBio, sendo que algumas das divulgações neste nível de ensino (Anos Iniciais) foram feitas por profissionais formados em Ciências/Biologia. Porém, esta realidade foi identificada igualmente por Moura e Leite (2020) em diversas plataformas de divulgação científica, resultando na detecção apenas de oito publicações referentes à promoção da alimentação saudável no currículo de instituições de ensino superior (IES), na formação de professores e/ou nas estratégias didáticas dos docentes pedagogos.

Os trabalhos sobre a EAN ocorreram também em modalidades de ensino, como os alunos da EJA, inclusive uma destas turmas consistiu na modalidade especial. É significativa a elaboração de trabalhos para as modalidades em ênfase no Ensino de Ciências/Biologia, visto que as produções nestes vieses ainda são incipientes nas pesquisas brasileiras (PEREIRA; OLIVEIRA; FERREIRA, 2019). No Ensino de Ciências/Biologia para os alunos da EJA, tornase necessário transpor diversas dificuldades conjuntas na preparação destes sujeitos, com o intento de uma formação emancipadora e eficientemente científica, as quais se obtém no estabelecimento de um olhar sensível aos indivíduos destacados (PARANHOS, 2017).

Relacionada a citação de Educação Básica, nos resultados anteriores, isso ocorreu em virtude do relato da construção de materiais pedagógicos pautados na promoção da alimentação saudável para a Educação Básica, no entanto sem informar os anos e os níveis de ensino destinados, ou seja, sem a delimitação do público. Houve situações também dos sujeitos das pesquisas serem professores da educação básica, licenciandos e bolsistas de iniciação à docência, fortificando a EAN na formação docente. 


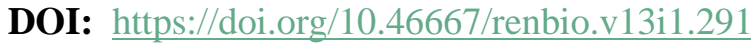

Os postulados do parágrafo anterior são relevantes devido a preparação para a promoção da alimentação saudável nas escolas ser um processo contínuo, necessitando a presença de docentes (formados e em formação) em iniciativas preparatórias para abordagem do tema (PEREIRA et al., 2017). Ampliando para a Educação em Saúde, as experiências fomentam para que a área seja melhor contemplada nas universidades, visto a sua baixa expressividade no currículo dos cursos de licenciatura para aplicação posterior nas instituições de ensino básico (VIEIRA; MORO, 2017).

Acerca dos cenários das pesquisas, existiram trabalhos realizados em escolas que promovem o ensino básico (37), em IES (4) e espaço não-formal (1). Enfatiza-se que em duas pesquisas foram utilizados mais de um dos espaços. Desta forma, teve-se produções contempladas em distintos âmbitos e, assim, a variabilidade de locais é fundamental na abordagem da alimentação saudável em diversos contextos que a circunda, como é proposto por Brasil (2009). Uma descrição dos trabalhos elencados se encontra na subseção a seguir.

\section{Debatendo com os produtos da caminhada}

Como esperado, os achados correspondem às propostas da presente pesquisa e, desta forma, é possível constituir um diálogo entre o currículo escolar, a formação de professores e as estratégias didáticas. No intento de uma coerente discussão entre as pesquisas, traçamos a divulgação dos dados a partir da sequência citada. Esta sequenciação aconteceu porque entendemos que o currículo determina os assuntos a serem ensinados, a formação de professores prepara para a atuação e as metodologias de ensino perpassam os saberes.

Iniciando sobre o currículo, na pesquisa finalizada por Pereira e Silva (2014), eles questionaram a dois sujeitos (uma licencianda em Ciências Biológicas e uma professora) quanto à Educação Alimentar e Nutricional (EAN), nos quesitos de conceito, aplicação como disciplina obrigatória, formas de trabalho e relevância da temática. Conceituada, pelas pesquisadas, como uma maneira de aquisição do bem-estar e da saúde, houve divergência para a EAN em relação à forma de aplicação, visto a sua idealização como disciplina curricular obrigatória e a outra proposta como tema transversal.

A produção de disciplinas curriculares obrigatórias é uma interessante propositura para a promoção da alimentação saudável. Contudo, a respeito da inserção de mais disciplinas nas matrizes curriculares, professores formadores questionam de que forma tal inserção poderia ser feita sem extrapolar a carga horária e sobrecarregar os alunos (MOURA; SOUSA; MENEZES, 2019), ressaltando também a discussão de outros temas urgentes na sociedade. Porém, Gatti (2013) menciona que é necessária uma revolução nos currículos escolares, no tocante a extinguir a sua fragmentação e a contemplar em melhores contextos os saberes necessários para a ação docente. Tais ponderações são relevantes na tentativa de melhorar a sintonia entre a formação de professores e os alunos da educação básica. 


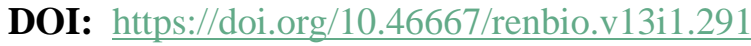

Relacionada a sua aplicação transversal, esta incide em perpassar o tema alimentação saudável por todos os componentes curriculares obrigatórios. Estas adições vêm ocorrendo ao longo das políticas públicas educacionais, começando com a sua tímida inserção nos Parâmetros Curriculares Nacionais, dentro do contexto da Saúde (BRASIL, 1997b) e continuando com as decisões governamentais posteriores da EAN como tema transversal nas escolas (BRASIL, 2013; BRASIL, 2018; BRASIL, 2019b). Os documentos enfatizam que os temas transversais não objetivam produzir mais disciplinas curriculares, mas em adicionar temas relevantes sociais em pauta de discussão. Assim, a pesquisa de Pereira e Silva (2014) contribui no debate de diferentes visões de abordagem da EAN no currículo.

No tocante aos trabalhos sobre formação docente, houve escritos em diversos âmbitos. Com início no destaque das produções concluídas, enfatiza-se a divulgação de um Trabalho de Conclusão de Curso, onde Verona e Costa (2018) fizeram uma pesquisa nos anos finais do ensino fundamental sobre à promoção das vitaminas. As autoras identificaram que embora haja o ensino de temas da alimentação na educação básica, estes competem com interferências externas, como as propagandas de televisão. No trabalho de Cruz et al. (2012) foi realizado um levantamento das informações prévias dos alunos envolvendo a alimentação e a nutrição, onde se destacou o conhecimento dos alunos sobre EAN, mas preferindo alimentos "menos saudáveis". Outra pesquisa neste teor foi feita por Santos et al. (2016) com professores de Ciências/Biologia quanto aos seus saberes de cuidados alimentares, de acordo com os postulados de segurança alimentar do PNAE (Lei de $\mathrm{n}^{\circ}$ 11.947/2009), onde associaram o tema saúde com viés higienista e para a prevenção de doenças.

Os escritos apontam que é preciso uma eficiente preparação de professores, visto que os docentes e discentes possuem saberes insatisfatórios referente a alimentação saudável, situação semelhante dos achados de Magalhães e Porte (2019). As formações, identificadas nos achados, aconteceram com valorização dos saberes culturais, a saber: os pesquisadores Ferreira, Magacho e Nascimento Junior (2016) realizaram oficinas com perspectiva interdisciplinar de alimentos energéticos (mel, cana-de-açúcar, milho e mandioca). Relacionado aos relatos de experiências formativas, Lima et al. (2016), em um projeto de extensão, também promoveram oficinas voltadas ao tema alimentação, relacionando-a ao consumo e a sociedade; e Barbosa, Salomão e Selles (2018) propuseram, em um programa de monitoria, uma sequência didática sobre a alimentação saudável, na qual ainda que tivesse um foco sanitarista, esta foi contextualizada em diversos aspectos da formação cidadã.

Observa-se o crescimento de formações acadêmicas referentes a EAN, o que contribui em sua promoção correta e em todos os aspectos ao ser divulgada. Outros trabalhos de preparação docente consistiram nas produções e reflexões de práticas metodológicas, as quais fazem parte da formação pedagógica de professores, como exemplo, constatamos as seguintes investigações em andamento: Mendes et al. (2014) relataram a produção, por graduandos, de um jogo de tabuleiro referente aos saberes científicos dos nutrientes; enquanto isso, Souza et al. (2016) mencionaram a produção de um guia de práticas metodológicas com base no filme "Tá chovendo hambúrguer"; e Soares, Pires e Silva (2018) contaram a construção 


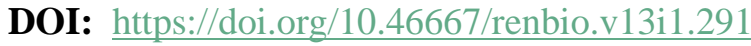

de uma cartilha sobre o açaí pelos alunos de uma disciplina da graduação, com o intento de valorização da cultura alimentar da Amazônia. Com pesquisa concluída, Gonçalves et al. (2018) elaboraram um jogo da memória relacionado aos alimentos e nutrientes, onde na reflexão pelos participantes (bolsistas de iniciação à docência e docentes da educação básica) a atividade foi relevante, contribuindo no desenvolvimento de habilidades profissionais.

Os pressupostos mostram a promoção da alimentação saudável em diversos contextos, como em disciplinas específicas da graduação, pesquisas científicas, programas de monitoria, extensão e formação inicial docente. Tal enunciação demarca várias iniciativas com a presença da EAN, como é norteado por Brasil (2012), e mostra a preocupação em uma eficiente preparatória científica e pedagógica para subsídios na atuação docente, conjuntura divergente nos espaços de instrução dos profissionais desta área (BEZERRA, 2018).

As produções que remetem à formação docente também relatam as suas formas de atualização dos conhecimentos pedagógicos e científicos. De acordo com as averiguações científicas finalizadas de Gomes, Poian e Goldbach (2007), a maioria dos seus pesquisados, professores de Ciências/Biologia, utiliza bases científicas para atualização dos informes. Os dados, apesar de favoráveis e instigadores à promoção da EAN, são surpreendentes, em virtude da contrariedade dos achados em outra pesquisa, ou seja, as atualizações de conhecimento e preparações docentes não ocorrem com auxílio de bases científicas (FERNANDEZ; SILVA, 2008). Entretanto, deve-se incitar o uso destas fontes para o suporte docente, no intuito de melhor preparação científica e pedagógica em suas atuações.

No quesito práticas metodológicas de ensino, apareceram numerosas produções e sugestões. Como relato de experiência, estas contemplaram: visitas a um supermercado para análises de rótulos dos alimentos - espaços não-formais (SOUZA; CHAVES; OLIVEIRA, 2010), o uso de fotografias (CARNEIRO et al., 2014), levantamento de informes prévios da alimentação dos alunos, propiciando planejamento com o tema (MARINHO et al., 2014), unidades/sequências didáticas (LEITE; ZANCUL; MÓL, 2016; MOREIRA et al., 2016), situações de estudo - criação de cardápios para doentes/conceitos alimentares e nutricionais (ANDRADE; BOFF, 2016; VITORIANO et al., 2014), buscas do desperdício alimentar e promoção da EAN em banners, folders e cartazes (SILVA et al., 2016), jogos didáticos, horta vertical e redação (FARO et al., 2016), construção de pirâmides alimentares (MONTENEGRO; ARAÚJO; PETROVICH, 2014; RIBEIRO et al., 2016), compra imaginária de alimentos e construção de documentário pelos alunos - utilização das tecnologias de informação e comunicação (TERRA; GOMES, 2016) e histórias em quadrinhos (FREITAS et al., 2016).

As proposições já apresentam a EAN em diversas metodologias de ensino. Outras práticas corresponderam: experimentos (MONTEIRO et al., 2018), paródias (MELO et al., 2018), horta orgânica (ARAÚJO, 2018) e gêneros textuais (NUNES; PESSOA, 2018). Houve também relatos de pesquisas, sendo finalizadas as seguintes: aplicação de jogos e dinâmicas (ZANCUL, 2007), diários de registro (CARMO; JUCÁ, 2010), júri simulado sobre o colesterol - vilão ou herói? (SOUSA et al., 2014), realização de entrevista para descoberta dos hábitos 


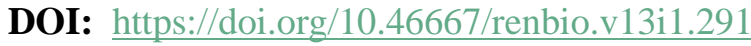

alimentares de terceiros (COSTA, 2014), levantamento de informações prévias dos hábitos alimentares dos alunos (CARVALHO; MACHADO, 2014; MARTINS et al., 2014); unidades/sequências didáticas (LIMA; RODRIGUES; FERREIRA, 2018; MACHADO; FRAIHA-MARTINS, 2018; SILVA; MACIEL, 2018) e horta orgânica (PANTOJA et al., 2018). Por fim, Coan e Amorin (2018) apresentaram uma pesquisa em andamento referente a elaboração de um roteiro didático para o conhecimento dos múltiplos usos do milho.

Diante aos achados, destaca-se a presença da alimentação saudável em diversas práticas metodológicas, contribuindo em sua promoção. Os trabalhos colaboram na divulgação de metodologias de ensino a outros docentes, os quais terão conhecimento da aplicação, das experiências, das dificuldades, dos êxitos e da relevância das propostas, além de ampliar a EAN a mais de um contexto da formação cidadã, como é proposto por Boog (2013). Há casos em que uma única metodologia pode não contemplar a todos os contextos, entretanto, a variabilidade de técnicas metodológicas favorece tal abordagem (MOURA et al., 2020).

Isso se deve pela entrada da temática nas áreas de formação e prática docente e saindo da exclusividade de abordagem técnica que geralmente ocorre na área da nutrição, com enfoque biomédico (CERVATO-MANCUSO; VINCHA; SANTIAGO, 2016). Outra contribuição dos achados se deu na implementação de práticas educativas desde a inserção dos alunos nas escolas, em que segundo Prado et al. (2016) deve ser promovida de forma contínua e permanente, destacando o uso diversas ações pedagógicas e inserindo alunos e docentes em saberes cotidianos.

As afirmações são corroboradas ao constatar os conteúdos envolvidos nas práticas metodológicas. Apesar de algumas atividades ainda terem o foco biomédico, a predominância de trabalhos foi com propostas de inclusão da alimentação saudável em todos os contextos de vida dos alunos, promovendo uma EAN em todos os seus aspectos. Isso representa ações e reconhecimento docente em expandir o Ensino de Ciências/Biologia.

A expansão da relevância do Ensino de Ciências/Biologia para a formação cidadã dos alunos é de fundamental relevância neste processo. Krasilchik (2004) comenta que a preparação exercida por tal ensino precisa cooperar no contato do aluno com a realidade, intervindo com ética, respeito e responsabilidade nas suas relações com o mundo. Isso mostra que não se deve dissociar o Ensino de Ciências/Biologia dos contextos de vida dos discentes em quesitos de sociedade, tecnologia e o meio ambiente (SASSERON; CARVALHO, 2008). Neste sentido, as metodologias destacadas ao longo das publicações na SBEnBio auxiliam nesta promoção, amparando as fragilidades oriundas da formação inicial de professores, em especial, na tomada de posições e convívio com divergências opinativas (SILVA; KRASILCHIK, 2013).

É precípuo destacar que alguns dos trabalhos identificados buscaram relações interdisciplinares, como a produção de histórias em quadrinhos, redações, aplicação de gêneros textuais, paródias, entre outras atividades. Desse modo, essa realidade torna-se relevante pelo diálogo das Ciências com outras áreas do conhecimento, articulando saberes em diferentes 
DOI: https://doi.org/10.46667/renbio.v13i1.291

linguagens (CACHAPUZ, 2014). As prerrogativas não foram ações exclusivas dos professores de Ciências, mas também de docentes de outras áreas do conhecimento que realizaram parcerias de divulgação do saber científico, como foi identificado em algumas das produções analisadas, refletindo no avanço do Ensino de Ciências/Biologia.

\section{Considerações finais}

Mediante as problemáticas de saúde na atualidade em virtude dos hábitos alimentares inadequados dos brasileiros, torna-se preciso sensibilizar a população, com o intento da efetivação de uma Educação Alimentar e Nutricional (EAN). Contudo, na educação, a alimentação saudável necessita de amplas explanações e reflexões para a sua inserção nas escolas. Assim, ponderar quanto às propostas curriculares, à formação de professores e às estratégias didáticas são de caráter significativo nas investigações desta temática científica, sobretudo no Ensino de Ciências/Biologia, em razão deste tema estar melhor explícito nesta área do conhecimento.

Realizado o levantamento bibliográfico em publicações da Associação Brasileira de Ensino de Biologia (SBEnBio), constatou-se trabalhos nos vieses apresentados. Em minoria, a publicação sobre o currículo mostra o debate entre uma licencianda e uma professora quanto às diferentes formas da sua inserção, o que se considera relevante nas discussões de promoção da alimentação saudável, inclusive para identificar a sua valorização pelos pesquisados ao expandi-la no currículo - forma transversal ou como disciplina curricular obrigatória.

O debate desta temática abrange também a formação de professores, os quais discutem em diversos programas de formação complementar docente (monitoria, extensão, iniciação à docência) e disciplinas curriculares obrigatórias sobre a sua promoção nas escolas. Isso possibilita observar o quão a abordagem da EAN vem aumentando nos espaços de preparação docente, propiciando diálogos na formação inicial e continuada de professores, bem como agrega saberes científicos e pedagógicos aos profissionais envolvidos.

No viés final, estratégias didáticas, houve a divulgação, em maioria, de muitas práticas metodológicas de ensino sobre a promoção da alimentação saudável. As estratégias didáticas apresentadas adicionaram a EAN em vários aspectos da formação cidadã, como o cultural, o social, o político, o econômico, entre outros. Tal identificação corrobora a real mudança necessária no Ensino de Ciências/Biologia e de suas temáticas científicas, como a EAN, em que devem perpassar amplos âmbitos da realidade discente, e não apenas o biológico.

A variabilidade de métodos de ensino, tanto para a educação básica quanto para a formação de professores, reflete na melhor preparação dos licenciandos, discentes e professores da educação básica. Outrossim, o Ensino de Ciências/Biologia passa a ser visto com diversos olhares, até mesmo associando-se a outras áreas do conhecimento, como ocorreu nos trabalhos resultantes de diversas parcerias em prol de atividades interdisciplinares para os alunos. Esta vertente possibilita a apresentação da EAN e das Ciências em múltiplas linguagens. 
DOI: $\underline{\text { https://doi.org/10.46667/renbio.v13i1.291 }}$

Embora os achados desta investigação tenham sido favoráveis, nota-se a necessidade de se expandir ainda mais a EAN. Primeiramente, é preciso que ela continue integrando os currículos escolares e até mesmo seja intensificada. Com isso, todos os estados brasileiros precisam realizar e/ou divulgar as suas experiências para visualização de práticas deste cunho por demais profissionais docentes e pesquisadores do país.

Por fim, destaca-se a possibilidade de se inserir a alimentação saudável em variados contextos e realidades (sujeitos, cenários, níveis e modalidades de ensino) por intermédio de adaptações metodológicas, as quais podem ser aplicadas ou adequadas por outros docentes. Nesta apreciação, a temática em ênfase avança no meio científico e acadêmico, na tentativa de sensibilizar os discentes quanto aos hábitos alimentares inadequados e, em consequência, na formação de sujeitos mais preparados cientificamente em sociedade.

\section{Referências}

ANDRADE, R. D. F.; BOFF, E. T. O. Situação de estudo: uma concepção problematizadora do espaço real de sala de aula. Revista de Ensino de Biologia, n. 9, p. 6703-6714, 2016.

ARAÚJO, A. Projeto de horta para disseminar o ensino de saúde: visando minimizar a contaminação por enteroparasitoses. In: ENCONTRO NACIONAL DE ENSINO DE BIOLOGIA - ENEBIO, 7. Belém - PA, 2018. Anais... Belém, PA: SBenBio, 2018.

ARAÚJO, M. A. O. A.; LEITE, R. C. M. L. Alfabetização científica nos anos iniciais do ensino fundamental: o que nos dizem os documentos oficiais. Revista ACTIO: Docência em Ciências, v. 4, n. 3, p. 165-184, 2019.

BARBOSA, M. M.; SALOMÃO, S. R.; SELLES, S. E. Práticas de conservação/decomposição de alimentos: ciência e cotidiano na formação docente. In:

ENCONTRO NACIONAL DE ENSINO DE BIOLOGIA - ENEBIO, 7. Belém - PA, 2018. Anais... Belém, PA: SBenBio, 2018.

BARDIN, L. Análise de conteúdo. São Paulo: Edições 70, 2011, 229 p.

BEZERRA, J. A. B. Educação alimentar e nutricional: articulação de saberes. Fortaleza: UFC, 2018, $120 \mathrm{p}$.

BOOG, M. C. F. Educação em nutrição: integrando experiências. Campinas, SP: Komedi, 2013, 268 p.

BRASIL. Ministério da Educação. Diretrizes Curriculares Nacionais da Educação Básica. Brasília, DF: Ministério da Educação, 2013.

BRASIL. Ministério da Educação. Diretrizes Curriculares Nacionais para os Cursos de Bacharelado e Licenciatura em Ciências Biológicas. Parecer CNE/CP 1301/2001. Brasília, DF: Ministério da Educação, 2001.

BRASIL. Ministério da Educação. Diretrizes Curriculares Nacionais para os Cursos de Graduação em Pedagogia, licenciatura. Parecer CNE/CP 1/2006. Brasília, DF: Ministério da Educação, 2006b. 


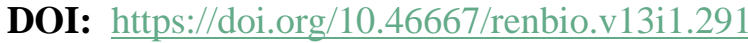

BRASIL. Ministério da Saúde. Estimativas sobre frequência e distribuição sociodemográfica de fatores de risco e proteção para doenças crônicas nas capitais dos 26 estados brasileiros e no Distrito Federal em 2018. Brasília, DF: Ministério da Saúde, 2019a.

BRASIL. Lei n⿳0 1.010/2006. Estabelece as diretrizes para a Promoção da Alimentação Saudável nas Escolas de educação infantil, fundamental e nível médio das redes públicas e privadas, em âmbito nacional. Brasília, DF: Ministérios da Saúde e Educação, 2006a.

BRASIL. Lei $\mathbf{n}^{0}$ 11.947/2009. Dispõe sobre o atendimento da alimentação escolar e do Programa Dinheiro Direto na Escola aos alunos da educação básica. Brasília, DF: Ministério da Educação,2009.

BRASIL. Lei no 13.666/2018. Altera a Lei no 9.394, de 20 de dezembro de 1996 (Lei de Diretrizes e Bases da Educação Nacional), para incluir o tema transversal da educação alimentar e nutricional no currículo escolar. Brasília, DF: Ministério da Educação, 2018.

BRASIL. Ministério do Desenvolvimento Social e Combate à Fome Marco de referência de educação alimentar e nutricional para as políticas públicas. Brasília, DF: MDS, 2012.

BRASIL. Ministério da Educação. Parâmetros Curriculares Nacionais: ciências naturais. Brasília, DF: MEC-Secretaria de Educação Fundamental, 1997a.

BRASIL. Parâmetros Curriculares Nacionais: meio ambiente e saúde. Brasília: MECSecretaria de Educação Fundamental, 1997b.

BRASIL. Temas contemporâneos transversais na BNCC: contexto histórico e pressupostos pedagógicos. Brasília, DF: Ministério da Educação, 2019 b.

BUSS, P. M.; CARVALHO, A. I. Desenvolvimento da promoção da saúde no Brasil nos últimos vinte anos (1988-2008). Ciência \& Saúde Coletiva, v. 14, n. 6, p. 2305-2316, 2009.

CACHAPUZ, A. F. Arte e ciência no ensino das ciências. Interacções, n. 31, p. 95-106, 2014.

CACHAPUZ, A. F. Do ensino das ciências: seis ideias que aprendi. In: CARVALHO, A. M. P.; CACHAPUZ, A. F.; GIL-PÉREZ, D. (Org.). O ensino das ciências como compromisso científico e social: os caminhos que percorremos. Perdizes, SP: Cortez, 2012. p. 11-32.

CACHAPUZ, A.; GIL-PÉREZ, D.; CARVALHO, A. M. P.; VILCHES, A. (Org.). A necessária renovação do ensino de ciências. 3.ed. São Paulo, SP: Cortez, 2011. 264 p.

CAMPOS, L. M. L.; MIRANDA, E. M.; KAPP, A. M.; DINIZ, R. E. S. Perspectivas para a educação científica: o que dizem especialistas da área de ensino de ciências. Indagatio Didactica, v. 11, n. 2, p. 771-786, 2019.

CARMO, J. S.; JUCÁ, R. N. Uso de registros diários como instrumento de avaliação na abordagem do tema conservação dos alimentos. Revista de Ensino de Biologia, n. 3, p. 338$349,2010$.

CARNEIRO, M. A. M.; WALLIER, P.; GOODMANN, T.; VASCONELLOS, G. F. Você é o que você come: uma questão transdisciplinar. Revista de Ensino de Biologia, n. 7, p. 5434-5445, 2014. 
DOI: https://doi.org/10.46667/renbio.v13i1.291

CARVALHO, D. S.; MACHADO, V. M. Hábitos alimentares e nutricionais de jovens do ensino médio em uma escola pública de Campo Grande/MS. Revista de Ensino de Biologia, n. 7, p. 1483-1494, 2014.

CERVATO-MANCUSO, A. M; VINCHA, K. R. R.; SANTIAGO, D. A. Educação Alimentar e Nutricional como prática de intervenção: reflexão e possibilidades de fortalecimento. Revista de Saúde Coletiva, v. 26, n. 1, p. 225-249, 2016.

CHAVES, L. G.; MENDES, P. N. R.; BRITO, R. R.; BOTELHO, R. B. A. O programa nacional de alimentação escolar como promotor de hábitos alimentares regionais. Revista de Nutrição, v. 22, n. 6, p. 857-866, 2009.

CHAVES, L. G.; SANTANA, T. C. M.; GABRIEL, C. G.; VASCONCELOS, F. A. G. Reflexões sobre a atuação do nutricionista no Programa Nacional de Alimentação Escolar no Brasil. Ciência \& Saúde Coletiva, v. 18, p. 917-926, 2013.

COAN, C. M.; AMORIN, M. B. Perspectivas da alfabetização científico-tecnológica ampliada para superar dificuldades do ensino de botânica na educação básica. In: ENCONTRO NACIONAL DE ENSINO DE BIOLOGIA - ENEBIO, 7. Belém, PA, 2018. Anais... Belém, PA: SBenBio, 2018.

COSTA, R. R. O ensino de ciências na perspectiva histórico-crítica: o ensino de nutrição no $8^{\circ}$ ano do ensino fundamental. Revista de Ensino de Biologia, n. 7, p. 6435-6446, 2014.

CRUZ, A.; KOH, C.; VIANA, M. G.; MATOS, S. A. Levantamento dos conhecimentos prévios de alunos do ensino fundamental sobre nutrição humana. Revista de Ensino de Biologia, n. 5, p. 1-8, 2012.

DELIZOICOV, D.; ANGOTTI, J. A.; PERnAMBUCO, M. M. C. A. Ensino de Ciências: fundamentos e métodos. 5.ed. São Paulo, SP: Cortez, 2018, 288 p.

FARO, R. M.; LOPES, C. M.; SOUZA, T. M.; LIMA, M. J. G. S. A abordagem do tema alimentação como prática socioambiental: relato de atividades desenvolvidas no CAp UFRJ. Revista de Ensino de Biologia, n. 9, p. 2256-2266, 2016.

FERNANDEZ, P. M.; SILVA, D. O. Descrição das noções conceituais sobre os grupos alimentares por professores de $1^{\mathrm{a}}$ a $4^{\mathrm{a}}$ série: a necessidade de atualização dos conceitos. Ciência \& Educação, v. 14, n. 3, p. 451-466, 2008.

FERREIRA, L. N.; MAGACHO, L. S. NASCIMENTO JUNIOR, A. F. Análise das atividades formativas desenvolvidas pelo PIBID: uma proposta unificadora, contextualizada, interdisciplinar e transversal na formação inicial de professores de Ciência e Biologia.

Revista de Ensino de Biologia, n. 9, p. 5833-5844, 2016.

FIGUEIRA, M. R.; LIMA, J. G. S.; SELLES, S. E. A temática da alimentação na interface ensino de ciências/educação ambiental. Revista de Ensino de Biologia, n. 9, p. 6155-6166, 2016.

FREITAS, C. A. PEREIRA, L. L.; AUGUSTO, R. P.; ROCHA, R. O. A história em quadrinhos na educação em ciências: multimodalidade, letramento e ludicidade. Revista de Ensino de Biologia, n. 9, p. 3374-3384, 2016. 


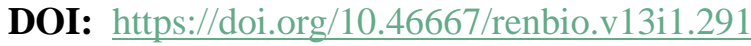

GATTI, B. A. Educação, escola e formação de professores: políticas e impasses. Educar em Revista, n. 50, p. 51-67, 2013.

GOMES, M. C.; POIAN, A. T.; GOLDBACH, T. Revistas de divulgação científica: concepções sobre os temas alimentação-metabolismo energético. In: ENCONTRO NACIONAL DE ENSINO DE BIOLOGIA - ENEBIO, 2. Anais... Uberlândia, MG: SBenBio, 2007.

GONÇALVES, V. F.; SIQUEIRA, A. S.; ASSUNÇÃO, L. O. A.; PEREIRA, N. Q. Jogo didático "alimentos e nutrientes": uma proposta de atividade lúdica para o ensino fundamental. In: ENCONTRO NACIONAL DE ENSINO DE BIOLOGIA - ENEBIO, 7. Belém, PA, 2018. Anais... Belém, PA: SBenBio, 2018.

KRASILCHIK, M. Prática de ensino de biologia. São Paulo, SP: EDUSP, 2004, 200 p. LEITE, L. B. M.; ZANCUL, M. S.; MÓL, G. S. Propostas de ensino relacionadas com a promoção da alimentação saudável na escola. Revista de Ensino de Biologia, n. 9, p. 465476, 2016.

LIMA, E. M.; RODRIGUES, E. C. V.; FERREIRA, A. T. S. Estratégias para educação ambiental e alimentar no ensino de ciências. In: ENCONTRO NACIONAL DE ENSINO DE BIOLOGIA - ENEBIO, 7. Belém, PA, 2018. Anais... Belém, PA: SBenBio, 2018.

LIMA, M. J. G. S.; SOUZA, P. H. O.; SOARES, A. G.; ASSUMPÇÃO, T. L.; PEREIRA, A. O. Ciências e educação ambiental na educação infantil e séries iniciais: uma parceria universidade escola. Revista de Ensino de Biologia, n. 9, p. 7147-7157, 2016.

LIMA, T. C. S.; MIOTO, R. C. T. Procedimentos metodológicos na construção do conhecimento científico: a pesquisa bibliográfica. Revista Katálysis, v. 10, n. SPE, p. 37-45, 2007.

MACHADO, C. R. S.; FRAIHA-MARTINS, F. O ensino da síntese de proteínas: construindo conhecimento socialmente relevantes. In: ENCONTRO NACIONAL DE ENSINO DE BIOLOGIA - ENEBIO, 7. Belém, PA, 2018. Anais... Belém, PA: SBenBio, 2018.

MAGALHÃES, H. H. S. R.; PORTE, L. H. M. Percepção de educadores infantis sobre educação alimentar e nutricional. Cienc. Educ. v. 25, n. 1, p. 131-144, 2019.

MARINHO, R. S. S.; MANHÃES, L. L. A.; SILVA, L. G. M.; SANTOS, M. M.; BARRETO, C. M. B. Experiência didática envolvendo a interação dos alunos na construção do conhecimento sobre nutrientes. Revista de Ensino de Biologia, n. 7, p. 6610-6618, 2014.

MARTINS, N. G. BRANDÃO, F. A.; SOUZA, V. A.; MAIA, I. M.; SILVA, P. D. P.; LANZA, E. M.; SARAIVA, I. S. Análise e amostragem da quantidade de carboidrato, sódio e gordura dos principais alimentos consumidos por estudantes do ensino médio de uma escola pública de Betim em Minas Gerais, por bolsistas do PIBID. Revista de Ensino de Biologia, n. 7, p. 5986-5997, 2014.

MELO, N. S.; SANTOS, A. C. S.; DIAS, L. D. F.; MENDONÇA, I. V. S. Experiência lúdica em sala de aula na disciplina de ciências. In: ENCONTRO NACIONAL DE ENSINO DE BIOLOGIA - ENEBIO, 7. Belém, PA, 2018. Anais... Belém, PA: SBenBio, 2018. 


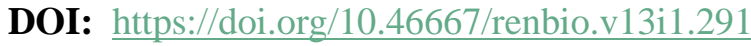

MENDES, C. C. M.; GOMES, M. D. S.; SILVA, G. M.; PARANHOS, J. D. N.; DANTAS, S. M. M. M. Proposta de jogo didático "na trilha dos alimentos". Revista de Ensino de Biologia, n. 7, p. 1138- 1146, 2014.

MENON, A. A.; COELHO NETO, J.; BERNARDELLI, M. S. Abordagens da alimentação e nutrição nas disciplinas do Ensino Fundamental: uma revisão sistemática de literatura. Research, Society and Development, v. 7, n. 8, p. 1-19, 2018.

MOHR, A. A natureza da educação em saúde no ensino fundamental e os professores de ciências. 2002. 410 f. Tese (doutorado em Educação) - Universidade Federal de Santa Catarina, Florianópolis, SC, 2002.

MONTEIRO, D. J. S. SANTOS, A. C. S.; FERREIRA, L. C. D.; MENDONÇA, I. V. S.; ROCHA, M. S. Aplicação do projeto seja um cientista em uma escola da zona rural de São Luís, Maranhão: um relato de experiência. In: ENCONTRO NACIONAL DE ENSINO DE BIOLOGIA - ENEBIO, 7. Belém, PA, 2018. Anais... Belém, PA: SBenBio, 2018.

MONTENEGRO, L. A.; ARAÚJO, M. F. F.; PETROVICH, A. C. I. Ludicidade em sala de aula: o jogo da pirâmide alimentar como uma proposta para o estudo dos alimentos e da nutrição no ensino médio. Revista de Ensino de Biologia, n. 7, p. 356-362, 2014.

MOREIRA, A. S.; ALMEIDA, D. Q.; CASTRO, E. B.; PACHECO, P. Q.; PESSOA, W. R. Ensinar ciências no ensino fundamental por meio de diferentes linguagens. Revista de Ensino de Biologia, n. 9, p. 7290-7297, 2016.

MOURA, F. N. S. LEITE, R. C. M.; MENEZES, J. B. F.; BARONI, W. S. G. V. Comer para ficar forte e crescer: a educação alimentar e nutricional em sequência didática. Revista Ciência e Desenvolvimento, v. 13, n. 1, 41-65, 2020.

MOURA, F. N. S.; LEITE, R. C. M. A educação alimentar e nutricional em questão: desdobramentos na formação inicial de professores pedagogos. Research, Society and Development, v. 9, n. 2, p. 109922141, 2020.

MOURA, F. N. S.; SOUSA, S. A.; MENEZES, J. B. F. Percepção da importância das tecnologias digitais por docentes dos cursos de formação inicial de professores no município de Crateús, CE. Revista Educação por Escrito, v. 10, n. 1, p. 29525, 2019.

NUNES, V. M.; PESSOA, W. R. Experiência formativa no ensino de ciências com o uso de gênero textuais na EJA modalidade ensino especial. In: ENCONTRO NACIONAL DE ENSINO DE BIOLOGIA - ENEBIO, 7. Belém, PA, 2018. Anais... Belém, PA: SBenBio, 2018.

OLISKOVICZ, K.; PIVA, C. D. As estratégias didáticas no ensino superior: quando é o momento certo para se usar as estratégias didáticas no ensino superior? Revista de Educação, v. 15, n. 19, p. 111-127, 2012.

PANTOJA, M. H. N.; CAXIAS, B. G. B.; PINTO, C. S.; MACHADO, D. R. S. "Plantando e aprendendo": horta escolar como abordagem da educação alimentar no ensino fundamental. In: ENCONTRO NACIONAL DE ENSINO DE BIOLOGIA - ENEBIO, 7. Belém, PA, 2018. Anais... Belém, PA: SBenBio, 2018.

PARANHOS, R. D. Ensino de biologia na Educação de Jovens e Adultos: o pensamento político-pedagógico da produção científica brasileira. 2017. 229 f. Tese (doutorado em 


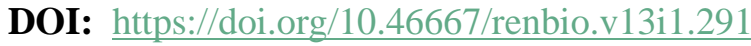

Educação) - Programa de Pós-Graduação em Educação, Universidade de Brasília, Brasília DF, 2017.

PEREIRA, D. S.; GOTTSCHALL, C. B. A.; TRINDADE, C. S.; BUSS, C.; MAGALHÃES, C. R. Formação continuada sobre alimentação e nutrição: análise da contribuição na prática docente. EmRede-Revista de Educação a Distância, v. 4, n. 1, p. 174-190, 2017.

PEREIRA, J. S. C.; SILVA, K. M. E. Educação alimentar e nutricional: um componente curricular ou um tema transversal? A visão da área de ensino biologia. Revista de Ensino de Biologia, n. 7, p. 4438-448, 2014.

PEREIRA, M. G.; OLIVEIRA, J. C. R. R.; FERREIRA, T. S. Análise de pesquisas em Educação em Ciências e Ensino de Biologia sobre Educação de Jovens e Adultos (EJA) em periódicos brasileiros. Revista Insignare Scientia-RIS, v. 2, n. 2, p. 100-114, 2019.

POZO, J. I.; CRESPO, M. Á. G. A aprendizagem e o ensino de ciências. 5.ed. Porto Alegre, RS: Artmed, 2009, 296 p.

PRADO, B. G.; FORTES, E. N. S.; LOPES, M. A. L.; GUIMARÃES, L. V. Ações de educação alimentar e nutricional para escolares: um relato de experiência. Demetra: alimentação, nutrição \& saúde, v. 11, n. 2, p. 369-382, 2016.

RAMOS, F. P.; SANTOS, L. A. S.; REIS, A. B. C. Educação alimentar e nutricional em escolares: uma revisão de literatura. Cadernos de Saúde Pública, v. 29, p. 2147-2161, 2013.

RIBEIRO, E. B.; GARCIA, V. F.; GONÇALVES, K. E. B.; ALMEIDA, M. D. S.;

CAVALCANTE, C. C.; MARTINS, M. M. M. C.; SILVA, F. R. F. A vivência do PIBID em sala de aula: a prática como contribuição para a formação inicial. Revista de Ensino de Biologia, n. 9, p. 3109-3120, 2016.

SANTOS, M. A. P.; OLIVEIRA, M. F. A.; MEIRELLES, R. M. S. Levantamento bibliográfico sobre a pesquisa "alimentação e nutrição" no ambiente escolar em duas bases de dados. Revista de Ensino de Biologia, n. 7, p. 5260-5270, 2014.

SANTOS, T. A. L.; VITA, E.; SPÓSITO, R. A.; MARISCO, G. A importância do ensino de microbiologia dos alimentos em escolas da rede pública: um enfoque para a saúde. Revista de Ensino de Biologia, n. 9, p. 2222-2231, 2016.

SASSERON, L. H.; CARVALHO, A. M. P. Almejando a alfabetização científica no ensino fundamental: a proposição e a procura de indicadores do processo. Investigações em ensino de ciências, v. 13, n. 3, p. 333-352, 2008.

SILVA, K. M. A.; MACIEL, J. C. S. Aspectos sociocientíficos no ensino de Biologia: uma sequência didática sobre alimentos transgênicos, convencionais e orgânicos. Revista de Ensino de Biologia, v. 11, n. 1, p. 5-24, 2018.

SILVA, P. F.; KRASILCHIK, M. Bioética e ensino de ciências: o tratamento de temas controversos-dificuldades apresentadas por futuros professores de ciências e de biologia. Ciência \& Educação, v. 19, n. 2, p. 379-392, 2013.

SILVA, T. S.; SILVA, M. J. F.; SILVA, J. G. M.; FARIAS, G. B. A construção de um trabalho investigativo coordenado pelo PIBID Biologia sobre o tema aproveitamento alimentar. Revista de Ensino de Biologia, n. 9, p. 1135-1146, 2016. 
DOI: https://doi.org/10.46667/renbio.v13i1.291

SOARES, J. P. V.; PIRES, E. T.; SILVA, C. A. F. O açaí na escola: cartilha didática para o ensino de ciências nos anos iniciais da educação básica. In: ENCONTRO NACIONAL DE ENSINO DE BIOLOGIA - ENEBIO, 7. Belém, PA, 2018. Anais... Belém, PA: SBenBio, 2018.

SOUSA, A. E. A.; SARMENTO, A. C.; MUNIZ, C. R. R.; GUIMARÃES, A. P. M. O estudo sobre qualidade de vida no ensino médio a partir da dinâmica de um júri simulado sobre colesterol. Revista de Ensino de Biologia, n. 7, p. 184-194, 2014.

SOUZA, L. C.; CHAVES, A. C.; OLIVEIRA, M. P. R. Conservação e rotulagem dos alimentos no supermercado: uma abordagem investigativa para alunos do ensino fundamental. Revista de Ensino de Biologia, n. 3, p. 2329-2337, 2010.

SOUZA, P. H. R.; MATTA, R. R.; MONERAT, C. A. A.; ROCHA, M. B.; BARROS, M. D. M. O uso do cinema no ensino de ciências: uma proposta a partir do filme "Tá Chovendo Hambúrguer". Revista de Ensino de Biologia, n. 9, p. 688-699, 2016.

TERRA, S. N. J.; GOMES, M. M. Currículo de Ciências: o reconhecimento de hábitos alimentares de alunos do oitavo ano do ensino fundamental. Revista de Ensino de Biologia, n. 9 , p. $3306-3315,2016$.

VERONA, M. F.; COSTA, T. Z. Vitaminas: um diagnóstico a partir de conhecimentos prévios. In: ENCONTRO NACIONAL DE ENSINO DE BIOLOGIA - ENEBIO, 7. Belém, PA, 2018. Anais... Belém, PA: SBenBio, 2018.

VIEIRA, F. B.; MORO, L. Educação em Saúde na formação inicial de professores de Biologia. Revista Docência do Ensino Superior, v. 7, n. 2, p. 34-49, 2017.

VITORIANO, N. C. F.; LIMA, B. R. R.; GOMES, R. R. A.; COSTA, I. A. S.; SOTERO, A. E. S. Aprendizagem baseada em problemas (ABPs) como estratégia de ensino aprendizagem sobre educação alimentar. Revista do Ensino de Biologia, n. 7, p. 5913-5923, 2014.

ZANCUL, M. S. Educação para a saúde: trabalho de educação alimentar e nutricional no ensino fundamental. In: ENCONTRO NACIONAL DE ENSINO DE BIOLOGIA - ENEBIO, 2. Anais... Uberlândia, MG: SBenBio, 2007. 